\title{
ИССЛЕДОВАНИЕ ПРОЦЕССА АГЛОМЕРАЦИИ ПЫЛЕВИДНОГО ГАЛУРГИЧЕСКОГО ХЛОРИДА КАЛИЯ
}

\author{
Черепанова Мария Владимировна',
}

syromyatnikova.maria@yandex.ru

\section{Кузина Евгения Олеговна',} zena322myname@mail.ru

\author{
Пойлов Владимир Зотович', \\ vladimirpoilov@mail.ru
}

\section{Мунин Дмитрий Андреевич', demon011093@yandex.ru}

\author{
Пермский национальный исследовательский политехнический университет, \\ Россия, 614990, г. Пермь, Комсомольский пр., 29.
}

\begin{abstract}
Актуальность. Образующийся в промышленности пылевидный галургический хлорид калия (КС1) смешивают с готовым кондиционным продуктом, что приводит кего пылимости и слеживаемости, а также потерям при транспортировании. Укрупнение пылевидного КС1 позволит повысить качество основного продукта за счет исключения стадии смешения разнофракционных компонентов. Агломерация формованием позволит получить продукт размером, близким к концентрату. Исследование особенностей агломерации с различными связующими позволит изучить их влияние на эффективность процесса и качество получаемого продукта.

Цель: изучение процесса формования пылевидного галургического хлорида калия и установление особенностей агломерации увлажненной тукосмеси с использованием связующих различного вида.

Методы. Для изучения состояния поверхности агломератов применяли электронно-сканирующую микроскопию с использованием режимов съемки BSE3D и SE при увеличении до 1500X; для определения элементного состава образовавшихся в процессе формования и сушки тукосмеси областей использовали рентгеноспектральный анализ; качество получаемого продукта оценивали с применением ситового анализа и метода измерения статической прочности на приборе ИПГ-1М.

Результаты. Установлено, что повышение влажности гранулируемой смеси способствует увеличению содержания товарной фракции до 84 \% и статической прочности до 10 Н/гранулу; использование связующих оказывает положительное влияние на качество продукта (повышая выход и прочность агломератов), при этом они могут иметь принципиально различные особенности процесса формования пылевидного галургического КС1, приводящие к образованию агломератов с существенными отличиями структуры, что подтверждено применением электронной микроскопии. Применение метасиликата натрия позволяет получить агломераты с плотным прилеганием частиц между собой, а иглообразные кристаллы оксида кремния, образовавшиеся за счет термического разложения $\mathrm{Na}_{2} \mathrm{SiO}_{3} \cdot 5 \mathrm{H}_{2} \mathrm{O}$, увеличивают шероховатость частиц $\mathrm{KC1}$, число центров кристаллизации и способствуют упрочнению связей в грануле. При использовании мелассы образующиеся агломераты имеют частицы КС1 С плотным контактом, но между ними видны остатки связующего; на их поверхности присутствуют скопления микрочастиц размером 10-30 мкм исходного пылевидного сырья в виде «панциря».
\end{abstract}

\section{Ключевые слова:}

Пылевидный галургический хлорид калия, гранула, агломерация, формование, электронная микроскопия, статическая прочность, товарная фракция, частица.

\section{Введение}

В процессе производства галургического хлорида калия в технологическом цикле на стадии сушки образуется до 20 \% пылевидной фракции хлорида калия (КС1), имеющего низкие показатели качества. На сегодняшний день в промышленности нетоварную фракцию смешивают с готовым кондиционным галургическим КC1, что приводит к пылимости и слеживаемости продукта, потерям при транспортировании, низкой усвояемости питательных веществ растениями [1-4]. Устранить указанные недостатки возможно за счет исключения смешения пылевидного КС1 с готовым галургическим КС1 и получения из него товарного продукта с размером частиц высокой прочности, близким к концентрату хлористого калия. В связи с этим актуальной проблемой является поиск путей укрупнения частиц пылевидного галургического KCl.

При анализе литературы установлено, что для укрупнения тонкодисперсных порошков возможно применение крупнотоннажных технологий, таких как:

- агломерация КС1 в аппаратах кипящего слоя (KC) [5-7];

- гранулирование пылевидного КС1 окатываниeм [8];

- гранулирование окатыванием с предварительным формованием увлажненной тукосмеси пылевидного КС1 [9].

При агломерации пылевидных фракций КС1 в псевдоожиженном слое [5] на твердые частицы напыляется через форсунки раствор связующего. Сoдержащаяся в каплях раствора жидкая фаза нали- 
пает на частицы, способствует их агломерации. Зародышами агломератов являются частицы либо их осколки, появляющиеся при дроблении (безрецикловые процессы), либо специально вводимые частицы ретура, отбираемые из выгружаемого из слоя гранулированного продукта (рецикловые процессы). В процессе гранулирования в объеме КС происходит интенсивное перемешивание пылевидной фракции и раствора связующего, приводящее к выравниванию температур и концентраций, это способствует снижению вероятности локального перегрева, который может нарушить протекание технологического процесса и ухудшить качество продукта. Поверхность контакта фаз велика и приближается к суммарной поверхности частиц. Текучесть псевдоожиженного слоя позволяет создавать аппараты непрерывного действия, в которых можно гранулировать вещества, находящиеся в различных агрегатных состояниях: порошки, пасты, растворы, суспензии и т. д. Аппараты с псевдоожиженным слоем имеют простое устройство, легко поддаются автоматизации и механизации [10].

Далее капли жидкой фазы испаряются. Обезвоживание единичной капли можно отнести к процессу совместного тепло- и массообмена, протекающему взаимосвязано внутри высушиваемого влажного материала. Макрокинетика гранулирования в КС имеет несколько особенностей, обусловленных тем, что в реальном аппарате псевдоожиженного слоя одновременно находится сотни тысяч и миллионы частиц. Эти частицы имеют различные размеры, и они движутся с различными скоростями и в разных направлениях. В связи с малым размером частиц исходного сырья основной проблемой проведения процесса агломерации в печах КС является трудность создания равномерной зоны интенсивного теплообмена, где частицы обдуваются горячими газами (толщина слоя от 5 до 50 размеров частиц), и эффективной зоны орошения порошка, так как при малом размере частиц практически невозможно провести равномерное распределение раствора связующего путем тонкого распыления (диспергирования).

За счет большой линейной скорости для создания равномерной зоны формирования агломератов и малого времени контактирования, недостаточного для сцепления частиц с раствором связующего, в промышленных печах КС процесс агломерации тонкодисперсных порошков сопровождается:

- большим уносом исходного пылевидного материала, что приводит к увеличению нагрузки на технологическое оборудование, предназначенное для очистки отходящего газа (циклоны, рукавные фильтры и т. д.);

- образованием крупных спеченных агломератов в зоне орошения (расположения форсунок) с недостаточной прочностью.

Проводить агломерацию пылевидного КС1 в аппаратах КС неэффективно и энергозатратно.

Гранулирование методом окатывания [8] характеризуется перемещением гранулируемой ту- космеси по поверхности аппарата, частицы смеси перекатываются по его стенкам. Окатывание является разновидностью структурной грануляции. Непрерывное движение гранулируемой смеси способствует зародышеобразованию и росту гранул, а также разрушению наименее прочных из них. При одновременном протекании этих противодействующих процессов образуются и сохраняются прочные и примерно одинаковые гранулы. При окатывании возможно сухое, граничное и влажное гранулирование с образованием твердых мостиков. Классическая схема окатывания: порошок, орошаемый связующим, подают во вращающийся аппарат, который установлен горизонтально или с небольшим наклоном. Смоченные частички агломерируются и, окатываясь, приобретают необходимые плотности и размеры.

Когда барабан вращается, часть смеси захватывается стенкой аппарата, поднимается и сползает вниз или падает с некоторой высоты. Степень заполнения аппарата, отношение величин внутреннего и внешнего трения, а также скорость вращения барабана определяют высоту подъема и количество захваченной гранулируемой смеси. При подъеме гранулируемая смесь движется совместно с барабаном, затем начинается скатывание, что приводит к увеличению размера, уплотнению и формированию гранул. В плане роста частиц для гранулируемого материала процесс окатывания является циклическим. Чем ближе разгрузочная часть барабана, тем медленнее происходит рост гранул. Готовый продукт представляет собой сферические гранулы диаметром от 1,0 до 5,0 мм. Свойства тукосмеси и содержание связующего влияют на величину гранул [10]. Недостатками метода окатывания являются сравнительно низкая прочность гранулята и сложность управления размерами гранул.

Для упрочнения гранул используют гранулирование окатыванием с предварительным формованием. В этом случае исходную порошкообразную смесь смешивают со связующим веществом и увлажняют. Полученную увлажненную тукосмесь формуют через перфорированные приспособления с заданными размерами ячеек. После чего проводят процесс окатывания и сушки. Исследования в этом направлении пока немногочисленны. В литературе $[4,11]$ представлены данные по получению минеральных удобрений из циклонной пыли флотационного КС1 методом окатывания с предварительным продавливанием тукосмеси через перфорированные ячейки. За счет использования предварительного формования увеличивается выход и прочность гранулята [12]. Характеристики получаемого продукта при этом зависят от природы и свойств связующего, влажности тукосмеси, параметров и режимов формования и окатывания.

При гранулировании пылевидных частиц окатыванием, независимо от наличия стадии формования, получаемый продукт будет иметь сферическую форму (диаметр 2-5 мм), а при его производ- 
стве необходимо вводить растворы реагентов, позволяющие сформировать прочную и плотную структуры, а также повысить эффективность гранулирования. Введение таких растворов приведет к снижению содержания КС1 в грануляте. Данный продукт может не найти широкого спроса, т. к. получаемый в промышленности галургический хлористый калий с фракционным сотовом до 1,0 мм применяется либо для получения калий-содержащих соединений, либо входит в состав тукосмесей, как компонент комплексных удобрений.

Применение агломерационного формования позволит получить продукт размером, близким к галургическому КС1. Данный способ имеет высокую производительность и эффективность, а также простое аппаратурное оформление, которое может быть установлено на действующем предприятии.

В связи с этим представляет научный и практический интерес исследование процесса агломерационного формования увлажненного пылевидного галургического КС1.

Для решения проблемы переработки пылевидной фракции галургического КС1 методом формования необходимо решить следующие задачи: изучить влияние степени увлажнения тукосмеси на эффективность агломерации, определить возможность агломерационного гранулирования пылевидного галургического КС1 без добавления и с добавлением связующего вещества; исследовать влияние содержания связующих веществ и содержания влаги при агломерации на статическую прочность и гранулометрический состав полученного продукта; изучить особенности процесса агломерации увлажненного пылевидного галургического КС1 с использованием связующих различного вида.

\section{Материалы и метод исследования}

Методика эксперимента по исследованию процесса агломерационного гранулирования путем формования заключалась в следующем: исходный пылевидный галургический хлорид калия с размером частиц менее 0,094 мм увлажняли до заданной величины и смешивали с расчетным количеством раствора связующего. Полученную смесь перемешивали до однородного состояния, после чего подвергали формованию на лабораторном вертикальном грануляторе через сетку с размером 1,0 мм. После этого агломерированный КС1 сушили при температуре $120{ }^{\circ} \mathrm{C}$ в течение 20 минут. Далее измеряли остаточную влажность продукта на анализаторе влажности MS-70 фирмы A\&D. Гранулометрический состав определяли с помощью ситового анализа и статическую прочность агломерированного продукта измеряли на приборе ИПГ-1М по известной методике [13]. Эффективность процесса агломерационного формования оценивали по следующим показателям: содержание фракции более 0,630 мм, статическая прочность и средний размер частиц продукта.
В качестве объекта исследования использовали пылевидный галургический хлорид калия (технический), образующийся на стадии сушки в сушильном отделении БКПРУ-1 ПАО «Уралкалий» (г. Березники, Пермского край). Пылевидный галургический КС1 - мелкие кристаллы серовато-белого цвета с размером менее 0,094 мм, имеет следующий состав (\% масс.): $\mathrm{KCl}$ не менее 98,2\%, $\mathrm{NaCl}$ не более $1,6 \%, \mathrm{H}_{2} \mathrm{O}$ не более $0,5 \%$.

Размер и морфологию частиц исходного пылевидного галургиче ского хлорида калия анализировали на электронном микроскопе S-3400N (Hitachi) (рис. 1, 2).

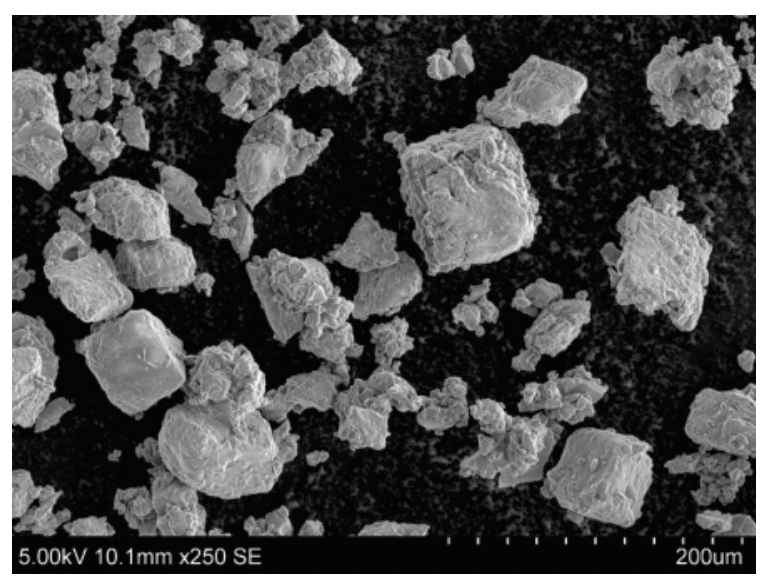

Рис. 1. Микрофотография частии пылевидного галургического КС1 (увеличение 250X)

Fig. 1. Microphotography of the particles of pulverized galurgical KC1 (magnification 50X)

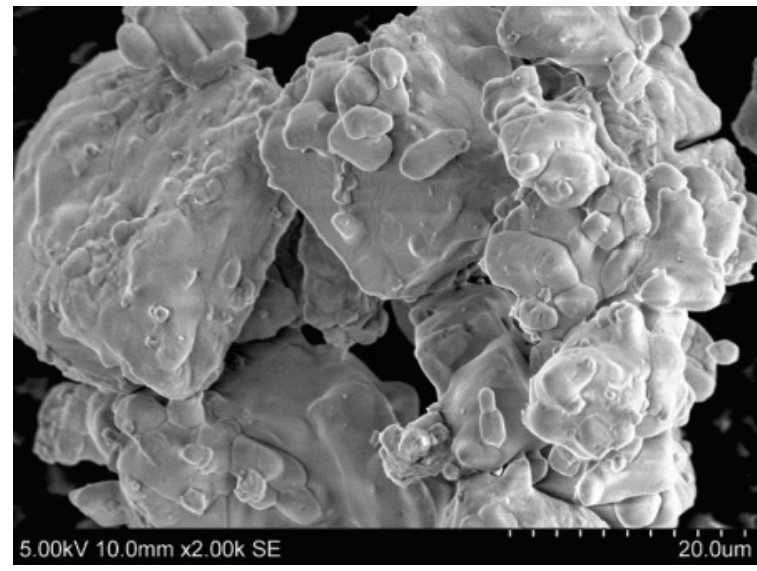

Pис. 2. Микрофотография частии пылевидного галургическогоКС1 (увеличение 2000X)

Fig. 2. Microphotography of the particles of pulverized galurgical KC1 (magnification 2000X)

Анализ микрофотографий (рис. 1, 2) показал, что частицы пылевидного галургического КС1 представляют собой агломераты, состоящие из кристаллов хлоридов калия и натрия с кубической, овальной, осколочной и неправильной формами. При этом поверхность частиц ровная и гладкая, без пор. Наличие кристаллов различных форм связано с тем, что пылевидный КС1 на стадии сушки продукта в печах КС подвергается термиче- 
скому и механическому разрушению, столкновениям частиц между собой и стенками аппарата. При этом частицы КС1 имеют большой разброс по размерам - от 50 нм до крупных агломератов размером более 90 мкм.

\section{Результаты исследований}

Степень увлажнения исходной смеси значительно влияет на качество получаемого продукта и эффективность агломерации $[14,15]$. Поэтому первоначально исследовали влияние ступени увлажнения пылевидного KC1 на гранулометрический состав, статическую прочность и средний размер частиц агломерированного продукта. Увлажнение проводили водой. Результаты исследований представлены в табл. 1.

Таблица 1. Влияние степени увлажнения пылевидного галурги ческого КС1 на гранулометрический состав, стати ческую прочность и средний разлер частии агломери рованного продукта

Table 1. Effect of moistening degree of the pulverized halurgic KC1 on particle size distribution, static strength and average particle size of the agglomerated product

\begin{tabular}{|c|c|c|c|c|}
\hline \multirow{3}{*}{$\begin{array}{l}\text { Размер фракции, мм } \\
\text { Fraction size, mm }\end{array}$} & \multicolumn{4}{|c|}{$\begin{array}{l}\text { Содержание фракции, \% } \\
\text { Fraction content, \% }\end{array}$} \\
\hline & \multicolumn{4}{|c|}{$\begin{array}{l}\text { Степень увлажнения пылевидного КС1, \% } \\
\text { Humidification degree of pulverized KC1, \% }\end{array}$} \\
\hline & 10 & 15 & 17,5 & 20 \\
\hline$+0,630$ & 10,49 & 26,10 & 56,80 & 84,70 \\
\hline$-0,630+0,355$ & 18,70 & 41,00 & 34,10 & 9,75 \\
\hline$-0,355+0,094$ & 59,30 & 29,50 & 7,43 & 3,98 \\
\hline$-0,094$ & 11,51 & 3,40 & 1,65 & 1,56 \\
\hline $\begin{array}{l}\text { Средний размер ча- } \\
\text { стиц, мм } \\
\text { Average size of partic- } \\
\text { les, mm }\end{array}$ & 0,30 & 0,45 & 0,58 & 0,65 \\
\hline $\begin{array}{l}\text { Средняя статическая } \\
\text { прочность, Н/гранула } \\
\text { Average static strength, } \\
\text { N/pellet }\end{array}$ & - & - & - & $10,2 \pm 0,2$ \\
\hline
\end{tabular}

При повышении степени увлажнения КС1 с 10 до $20 \%$ содержание фракции более 0,630 мм возрастает в 8 раз с 10,49 до 84,7 \%, а количество пылевидной фракции класса менее 0,094 мм снижается почти на 10 \% с 11,51 до 1,56 \%. Максималь- ный средний размер частиц получаемого агломерата 0,65 мм и статическая прочность 10,2 H/гранула получены при степени увлажнения $20 \%$. При степени увлажнения менее $20 \%$ статическая прочность агломератов очень мала. Увеличение степени увлажнения пылевидного КС1 способствует повышению пластичности исходной тукосмеси, а также положительно влияет на качество получаемого агломерированного КС1.

Вид и расход связующего являются существенным параметром проведения процесса. В качестве связующих использовали вещества, отличающиеся по своей природе: связующее органического происхождения - меласса (побочный продукт производства сахара), содержит 20-25\% воды, 9-10\% азотистых соединений (амидов), 58-60\% углеводов (сахаров) и 7-10\% золы [16, 17] и $10 \%$-й водный раствор метасиликата натрия $\left(\mathrm{Na}_{2} \mathrm{SiO}_{3} \cdot 5 \mathrm{H}_{2} \mathrm{O}\right)$ [18-20], минеральное неорганическое связующее, которое широко применяется как упрочняющая добавка.

Исследование вида и содержания связующего проводили при степени увлажнения КС1 20 \%, peзультаты исследований приведены в табл. 2.

Из анализа приведенных данных (табл. 2) следует, что вид, содержание и природа связующего оказывают значительное влияние на качество получаемого агломерата. Введение минерального неорганического раствора связующего метасиликата натрия эффективно только при его содержании более $1 \%$, происходит упрочнение агломератов до $19,23 \mathrm{H} /$ гранулу, но выход товарной фракции низкий (76-86 \%). В процессе сушки агломерата при повышенных температурах в присутствии воды (степень увлажнения 20 \%) связующее подвергается гидролизу.

Выделяющийся при гидролизе гель кремниевой кислоты обладает вяжущими свойствами [21]. Небольшого количества раствора метасиликата натрия (менее 1 \%) недостаточно для связывания пылевидных частиц галургического КС1.

Введение в увлажненную тукосмесь связующего мелассы содержанием $0,3 \%$ не приводит к повышению эффективности формования. Максимальный выход (содержание фракции более

Таблица 2. Влияние вида и расхода связующего на гранулометрический состав и статическую прочность аглолерированного КС1 Table 2. Influence of the type and consumption of the binder on granulometric composition and static strength of the agglomerated KC1

\begin{tabular}{|c|c|c|c|c|c|c|c|c|}
\hline \multirow{3}{*}{$\begin{array}{l}\text { Размер фракции, мм } \\
\text { Fraction size, mm }\end{array}$} & \multicolumn{4}{|c|}{$\begin{array}{l}\text { Содержание } 10 \% \text {-го раствора } \mathrm{Na}_{2} \mathrm{SiO}_{3} \cdot 5 \mathrm{H}_{2} \mathrm{O}, \% \\
\text { Content of } 10 \% \text { water solution } \mathrm{Na}_{2} \mathrm{SiO}_{3} \cdot 5 \mathrm{H}_{2} \mathrm{O}, \%\end{array}$} & \multicolumn{4}{|c|}{$\begin{array}{l}\text { Содержание мелассы, \% } \\
\text { Melasses content, \% }\end{array}$} \\
\hline & 0,3 & 0,5 & 0,7 & 1,0 & 0,3 & 0,5 & 0,7 & 1,0 \\
\hline & \multicolumn{8}{|c|}{ Содержание фракции, \% / Fraction content, \% } \\
\hline$+0,630$ & 76,13 & 75,43 & 83,33 & 86,35 & 72,30 & 87,30 & 95,13 & 96,8 \\
\hline$-0,630+0,355$ & 14,73 & 13,70 & 9,32 & 8,73 & 18,05 & 4,41 & 3,23 & 1,57 \\
\hline$-0,355+0,094$ & 7,72 & 9,31 & 6,25 & 5,85 & 8,38 & 7,67 & 1,28 & 1,22 \\
\hline$-0,094$ & 1,41 & 1,56 & 1,10 & 1,03 & 1,27 & 0,62 & 0,35 & 0,41 \\
\hline $\begin{array}{l}\text { Средний размер частиц, мм } \\
\text { Average particles size, mm }\end{array}$ & 0,62 & 0,62 & 0,64 & 0,65 & 0,61 & 0,65 & 0,68 & 0,69 \\
\hline $\begin{array}{l}\text { Средняя статическая прочность, Н/гранула } \\
\text { Average static strength, N/pellet }\end{array}$ & $12,3 \pm 0,2$ & $14,7 \pm 0,1$ & $17,6 \pm 0,3$ & $19,2 \pm 0,2$ & $11,5 \pm 0,2$ & $15,2 \pm 0,3$ & $22,2 \pm 0,3$ & $22,9 \pm 0,2$ \\
\hline
\end{tabular}


0,630 мм) 96,8 \% и статическая прочность агломерированного продукта $22,9 \mathrm{H}$ /гранула достигаются при использовании в качестве связующего мелассы с содержанием в тукосмеси 1,0 \%. Это можно объяснить тем, что меласса за счет своих свойств «склеивает» увлажненные частицы КС1 между собой, а на стадии сушки происходит их дополнительное упрочнение и цементация.

Для установления особенностей процесса агломерации увлажненного пылевидного $\mathrm{KC} 1$ с использованием различных связующих изучили структуру и морфологию агломерированного продукта на электронном сканирующем микроскопе с приставкой «Bruker» для рентгеноспектрального анализа. Ниже представлены микрофотографии агломератов, полученных с использованием раствора метасиликата натрия (рис. 3) и мелассы (рис. 4).

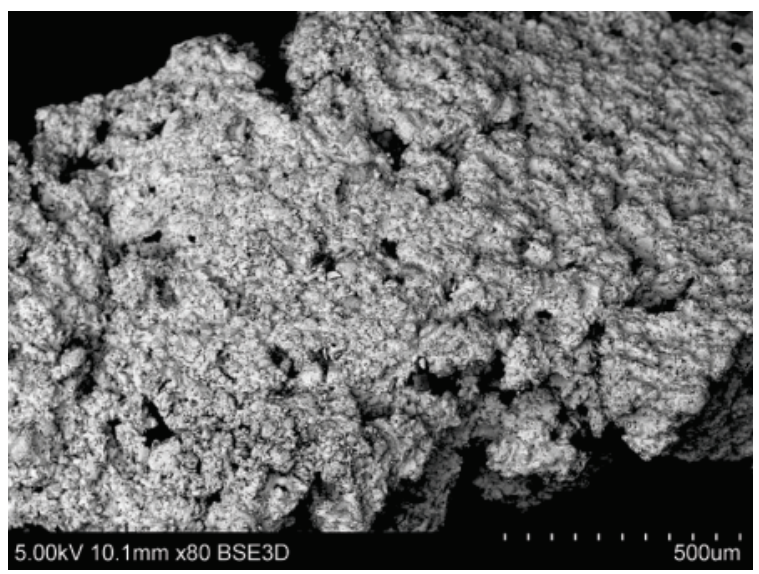

Рис. 3. Микрофотография агломерата, полученного из пылевид ного галургического КС1 с использованием метасилика та натрия (увеличение 80X)

Fig. 3. Photomicrograph of the agglomerate obtained from pulverized galurgical KC1 using sodium metasilicate (magnification $80 X)$

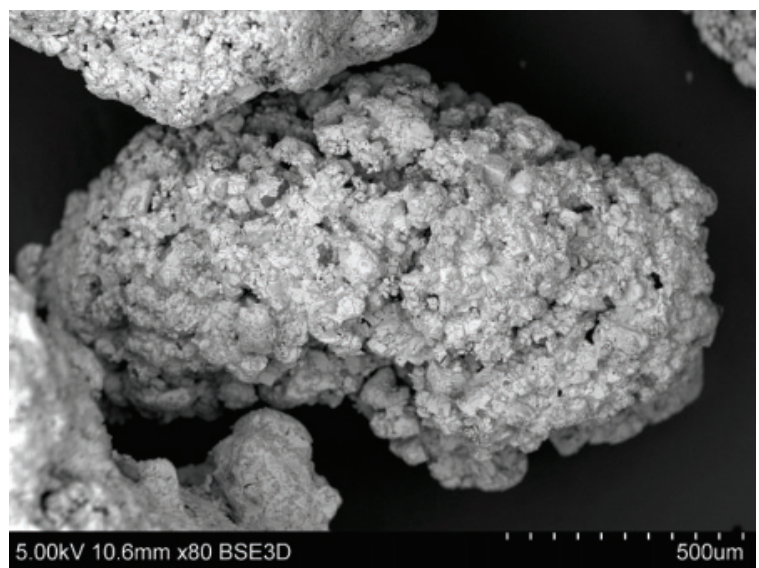

Рис. 4. Микрофотография агломерата, полученного из пылевид ного галургическогоКС1 с использованием мелассы (увеличение 80X)

Fig. 4. Photomicrograph of the agglomerate obtained from pulverized galurgical KC1 using melasses (magnification 80X)
Анализ микрофотографий (рис. 3,4$)$ показал, что у получаемых агломератов достаточно плотная упаковка, входящие в них частицы плотно прилегают друг к другу, за счет наличия солевых мостиков, но на их поверхности видны дефекты в виде трещин и каверн. Форма агломератов овальная, чаще неправильная, вытянутая. На поверхности более крупных частиц присутствуют мелкие осколочные частицы кубической, сферической, трапециевидной и неправильной форм. Сросшиеся контакты и солевые мостики между частицами упрочняют агломераты. При большем увеличении установлено, что агломераты, полученные с различными связующими, значительно отличаются.

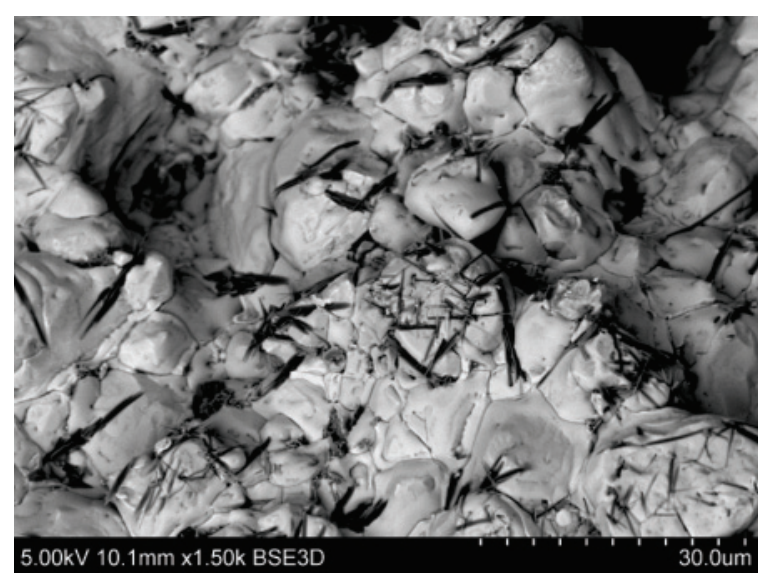

Pис. 5. Микрофотография частии агломерата, полученного из пылевидного галургического КС1 с использованием метасиликата натрия с форлованием (режим BSE3D, увеличение $1500 \mathrm{X}$ )

Fig. 5. Photomicrograph of the agglomerate particles obtained from pulverized galurgical KC1 using sodium metasilicate with molding (mode BSE3D, magnification 1500X)

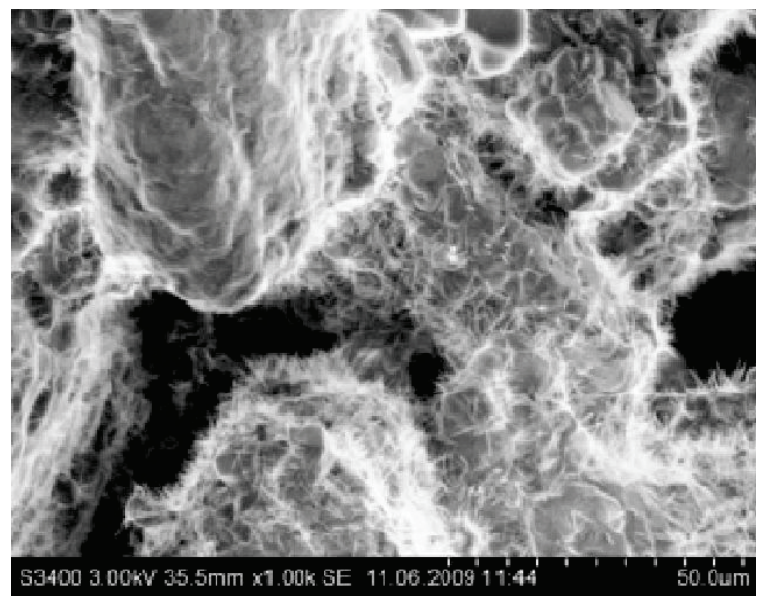

Pис. 6. Микрофотография частии агломерата, полученного из пылевидного галургического КС1 с использованием мета силиката натрия без формования (режим SE, увеличение 1000X)

Fig. 6. Photomicrograph of the agglomerate particles obtained from pulverized galurgical KC1 using sodium metasilicate without molding (mode SE, magnification 1000X) 
На рис. 5 приведены микрофотографии поверхности агломерата, полученного с $\mathrm{Na}_{2} \mathrm{SiO}_{3} \cdot 5 \mathrm{H}_{2} \mathrm{O}$, и видно плотную упаковку частиц КС1. Частицы в местах их соприкосновения сглажены. На поверхности видны иглообразные кристаллы (за счет съемки в режиме BSE3D они имеют черный цвет), характерные для соединений кремния [22].

На рис. 6 представлено изображение поверхности частицы КС1, полученной без формования с использованием метасиликата натрия. На поверхности частиц КС1, расположенных удаленно (на расстоянии) друг от друга, видны иглообразные кристаллы белого цвета (за счет съемки в режиме $\mathrm{SE}$ ). Из литературных данных известно, что частицы $\mathrm{SiO}_{2}$ имеют вытянутую, иглообразную форму [23]. При сравнении данных микрофотографий (рис. 5, 6) установлено, что процесс формования способствует получению плотных гранул с близким соприкосновением частиц КС1 в агломератах, имеющих высокую статическую прочность.

Можно предположить, что процесс агломерации галургического хлорида калия происходит следующим образом. Тонкодисперсные частицы хлорида калия растворяются частично парами воды и прилипают к поверхности других агломерируемых частиц. Далее следует стадия кристаллизации в точке контакта с формированием солевого мостика. Вводимый метасиликат натрия при быстром испарении воды с поверхности частицы образует кристаллы в виде игл, что приводит к повышению шероховатости частиц, упрочнению агломератов, а также способствуют присоединению к ним новых тонкодисперсных частиц. За счет термического разложения метасиликата натрия образуются новые центры кристаллизации, происходит заращивание мест контакта частиц КС1, образование крупных и прочных агломератов.

Основным условием образования игольчатых кристаллов силиката натрия является наличие высокой влажности (более 10 \%) высушиваемой тукосмеси. В процессе термогидролиза метасиликата натрия происходит образование оксида кремния [24]. Единичные кристаллы $\mathrm{SiO}_{2}$ представляют собой вытянутые шестигранные столбчатые кристаллы с пирамидальной (шести- или трехгранной) верхушкой. При этом за счет высокой скорости сушки в начальный момент процесса происходит быстрый рост кристаллов $\mathrm{SiO}_{2}$ в единицу времени. Образуются вытянутые столбчатые кристаллы в виде тонких игл. При идентичных условиях проведения исследований по получению агломерата из мелкодисперсного КС1 с метасиликатом натрия методом формования при низкой влажности тукосмеси образования иглообразных кристаллов не происходит, а получаемый продукт имеет низкую прочность и выход товарной фракции.

На рис. 7 представлена микрофотография поверхности агломерата KC1, полученного из пылевидного галургического хлорида калия с использованием мелассы с содержанием 0,7 \% при степени увлажнения $20 \%$ (с метками $\boldsymbol{\Delta}$ и $о$ в точках, в которых осуществляли рентгеноспектральный анализ).

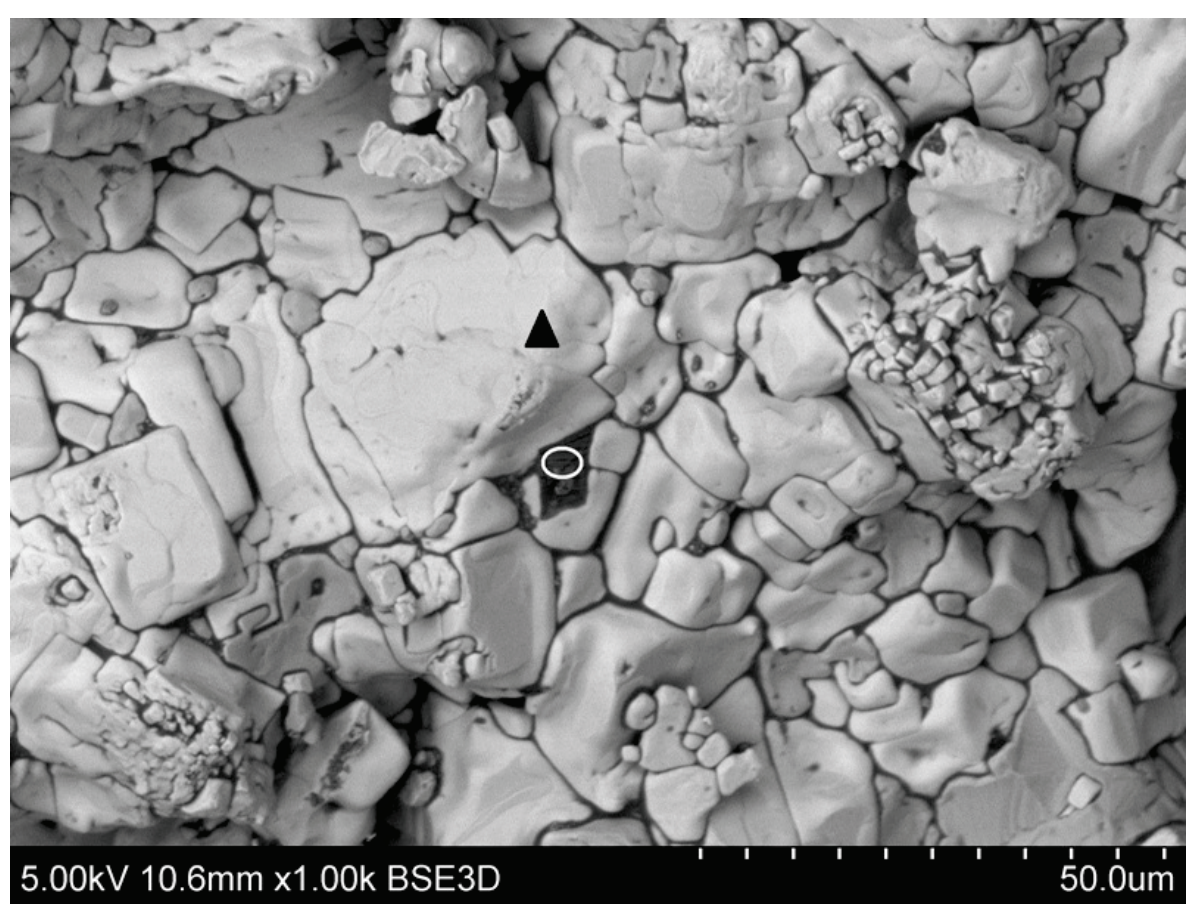

Puс 7. Поверхность агломерата, полученного из пылевидного галургического хлорида калия с использованиел мелассы (режил ВSEЗD, увеличение 1000X)

Fig. 7. Surface of the agglomerate obtained from pulverized halurgic potassium chloride using melasses (mode BSE3D, magnification 1000X) 
На поверхности агломерата видны частицы КС1 кубической, овальной и неправильной формы (белого цвета), со сглаженными гранями. Все частицы плотно соединены между собой, в местах их контакта видно наличие "соединителя» - вещество темного (черного) цвета, находящееся между граней КС1. Предположительно это остатки мелассы. Также на поверхности видны скопления мелкодисперсных частиц в виде «панциря», с наличием между нами вещества темного цвета.

На поверхности агломерата присутствует зона темного цвета, внедренная между плотно прилегающими частицами $\mathrm{KC} 1$, видимая часть имеет размеры $5 \times 8$ мкм. Проведенный рентгеноспектральный анализ показал, что данная область имеет следующий элементный состав (масс. \%): C 26,63, O - 13,69; $\mathrm{Na}-2,90 ; \mathrm{Cl}-30,29 ; \mathrm{K}-26,49$. Анализ участка поверхности агломерата, обозначенного меткой $\boldsymbol{\Delta}$, показал, что в нем присутствуют такие элементы, как $\mathrm{K}, \mathrm{Na}, \mathrm{Cl}$, и полностью отсутствует углерод.

Видимые на рис. 7 участки черного цвета являются остаточными соединениями мелассы, образовавшимися после сушки агломерата.

На основе полученных данных можно представить следующие особенности процесса агломерации увлажненного пылевидного галургического КС1 при использовании в качестве связующего мелассы. На первом этапе, на стадии увлажнения, грани частиц КС1 начинают растворяться и прилипать друг к другу. После введения в увлажненный КС1 мелассы, за счет ее повышенной вязкости и склеивающей способности, пылевидные частицы фиксируются друг с другом. Кристаллы 10-30 мкм сгруппировываются на поверхности агломерата, образуя скопления неправильной рыхлой формы в виде «панциря». За счет последующего агломерирования тукосмеси путем формования происходит уплотнение уже структурированной увлажненной смеси ее продавливанием через ячейки. В результате меласса, находясь между частицами КС1, укрепляет структуру агломератов. За счет последующей сушки происходит фиксация и цементация склеенных частиц. Помимо этого «липкая» меласса за счет собственных свойств и разложения образует много центров кристаллизации, способствующих упрочнению связей между частицами. В процессе формования и сушки происходит заращивание мест контакта и образование крупных прочных агломератов.

\section{Заключение}

В ходе исследований изучено влияние степени увлажнения на эффективность процесса агломерации. Установлено, что повышение содержания влаги в гранулируемой смеси приводит к увеличению содержания фракции более 0,630 мм до 84 \% , а статическая прочность агломератов достигает $10 \mathrm{H} /$ гранулу.

Определена возможность агломерации КС1 формованием без использования связующих. Однако их введение в тукосмесь способствует увеличению выхода товарной фракции более чем на $10 \%$ и упрочнению в 2 раза полученных агломератов.

Повышение содержания связующих оказывает положительное влияние на качество продукта. При введении 1 \% раствора метасиликата натрия статическая прочность увеличивается на 9 H/гранулу, а содержание крупной фракции - на $2 \%$. При формовании КС1 с 1 \% мелассы в продукте увеличивается на $12 \%$ выход и на 12 Н/гранулу прочность.

На основе проведенных исследований установлено, что в качестве связующих возможно применение различных по своей природе веществ. При этом данные соединения могут повышать прочность продукта, выход товарной фракции, увеличивать эффективность агломерации, но иметь принципиально различные особенности процесса гранулирования пылевидного галургического КС1.

За счет проведенного анализа микрофотографий поверхности агломератов, полученных из пылевидного галургического хлорида калия с использованием метасиликата натрия и мелассы, выявлены существенные отличия структуры частиц.

При использовании в качестве связующего метасиликата натрия образуются агломераты с плотным прилеганием частиц между собой, а на их поверхности видны иглообразные кристаллы оксида кремния, образовавшиеся за счет термического разложения $\mathrm{Na}_{2} \mathrm{SiO}_{3} \cdot 5 \mathrm{H}_{2} \mathrm{O}$, увеличивающие шероховатость частиц КС1, число центров кристаллизации и способствующие упрочнению связей в грануле. Установлено, что формование смеси способствует получению прочных агломератов плотной структуры, в которых частицы КС1 непосредственно соприкасаются между собой.

При использовании мелассы также образуются агломераты с плотным контактом частиц КС1, однако между ними видны остатки связующего (темные области на границах соприкосновения хлорида калия). На поверхности агломератов на участках с большим количеством мелассы присутствуют скопления (образования) частиц размером 10-30 мкм исходного пылевидного сырья в виде «панциря», т. е. меласса, распределяясь в тукосмеси по поверхности частиц, после гранулирования методом формования, плотно "склеивает» частицы, увеличивая прочность, а в местах ее избытка на поверхности образуются скопления тонкодисперсных частиц, приводящие к повышению выхода товарной фракции более 0,630 мм. 


\section{СПИСОК ЛИТЕРАТУРЫ}

1. Gebreslassie H.B. Effect of Potasium Fertilizer on Crop Production // Journal of Natural Sciences Research. - 2016. - V. 6. № 7. - P. 81-86.

2. Neshev N., Manolov I. Potassium fertilizer rate and source influence content, uptake and allocation of nitrogen, phosphorus and potassium in potato plants / Conference VIVUS - on Agriculture, Environmentalism, Horticulture and Floristics, Food Production and Processing and Nutrition. - Slovenia: Biotechnical Centre Naklo, 2017. - V. 4. - P. 1-6.

3. Влияние условий хранения и транспортировки на физико-механические свойства гранулированного хлорида калия / М.В. Черепанова, И.С. Потапов, В.З. Пойлов, К.В. Попова, С.Н. Алиферова // Вестник ПНИПУ. Химическая технология и биотехнология. -2012 . - № 13. - С. 35-42.

4. Назаров В.И., Макаренков Д.А. Гранулирование комплексных удобрений и реологические и физико-химические свойства компонентов // Вестник МГОУ. Естественные науки - 2011. № 4. - C. 143-148.

5. Improved method of manufacturing an agglomerated potassium chloride fertilizer: pat. USA № 2107702; reported 21.09.1934; publ. 08.02.1938. $-2 \mathrm{p}$.

6. Липин А.Г., Небукин В.0., Липин А.А. Капсулирование гранул в полимерные оболочки как метод создания минеральных удобрений с регулируемой скоростью высвобождения питательных веществ // Журнал ИГХТУ, Современные наукоемкие технологии. - 2017. - № 3 (51). - С. 86-91.

7. Возможности повышения эффективности переработки смесей промбытотходов путем гранулирования / А.С. Парфенюк, А.И. Кутняшенко, Д.И. Тасиц, Ш. Хайнрих, С.И. Антонюк // Экологические проблемы индустриальных мегаполисов: материалы III международной научно-практической конференции. - Украина: Донецк, 2010. - Т. 6. - С. 206-209.

8. Сковородников П.В., Черепанова М.В. Способы гранулирования органоминеральных удобрений // Вестник ПНИПУ. Химическая технология и биотехнология. - 2017. - № 3. C. $117-127$.

9. Iskandar A., Yuliasih I., Haryanto D.B. Effect of temperature and time on dry granulation process // International Journal of Research in Engineering and Technology. - 2014. - V. 2. P. 33-44.

10. Процессы гранулирования в промышленности / Н.Г. Вилесов, В.Я. Схрипков, В.Л. Ломазов, И.М. Танченко. - М.: Техника, 1976. - $192 \mathrm{c}$.

11. Федотова 0.А. Разработка технологии получения гранулированных NPK удобрений методом окатывания на основе сульфата аммония и хлорида калия, содержащего примеси фотореагентов: дис. ... канд. техн. наук. - Пермь, 2012. - 127 с.
12. Physicochemical properties of fertilizers available on market and possibility of production of blended fertilizers / A. Biskupski, S. Schab, A. Myka, M. Dawidowicz // Chemik. - 2012. - V. 66. P. 541-548.

13. ГОСТ 21560.2-82. Удобрения минеральные. Метод определения статической прочности гранул. - М.: ИПК Изд-во стандартов, 2003. -4 c.

14. Способ получения хлористого калия: пат. Рос. Федерация, № 2652256; заявл. 27.06.2017; опубл. 25.04.2018, Бюл. № $12 .-7$ c.

15. Gluba T. The effect of wetting liquid droplet size on the growth of agglomerates during wet drum granulation // Powder Technology. - 2003. - № 130. - P. 219-224.

16. Coal tar pitch and molasses blended binder for production of formed coal briquettes from high volatile coal / Q. Zhong, Q. Li, Y. Yang, T. Jiang // Fuel Processing Technology. -2017. V. 25. - P. 89-97.

17. Волков А.И., Жарский И.М. Большой химический справочник. - М.: Современная школа, 2005. - 608 с.

18. Microstructural and mechanical properties of silica - PEPEG polymer composite xerogels / M.M. Kulkarni, R. Bandyopadhyaya, B. Bhattacharya, A. Sharma // Acta Materialia. - 2006. № 54. - P. 5231-5240.

19. Vehmas T., Kanerva U., Holt E. Spray-dry agglomerated nanoparticles in ordinary portland cement matrix // Materials Sciences and Applications. - 2014. - V. 5. - P. 837-844.

20. Water content modifies the structural development of sodium metasilicate-activated slag binders / S.A. Bernal, R.S. Nicolas, S.J. van Deventer, J.L. Provis // ALCONPAT Journal. - 2015. V. 5. - P. 30-41.

21. Корнеев В.И., Данилов В.В. Растворимое и жидкое. - СПб.: Стройиздат, 1996. - 216 с.

22. Черепанова М.В., Пойлов В.З. Взаимодействие связующего силиката калия с примесными компонентами при формировании гранул $\mathrm{KCl}$ методом окатывания // Известия Томского политехнического университета. Инжиниринг георесурсов. 2017. - T. 328. - № 10. - C. 41-49.

23. Григорьев П.Н., Матвеев М.А. Растворимое стекло: получение, свойства и применение. - М.: Государственное издательство литературы по строительным материалам, 1956. - 443 с.

24. Филиппович Е.Н., Хацринов А.И., Скворцов А.В. Выбор оптимальных условий термической обработки диатомита Инзенского месторождения Ульяновской области для синтеза кристаллических силикатов натрия // Вестник Казанского технологического университета. - 2010. - № 5. - С. 83-86.

Поступила 25.12.2018 2.

\section{Информация об авторах}

Черепанова М.B., кандидат технических наук, доцент кафедры химические технологии Химико-технологического факультета Пермского национального исследовательского политехнического университета.

$\boldsymbol{K} \boldsymbol{y}$ зин $\boldsymbol{E}$.O., инженер кафедры химические технологии Химико-технологического факультета Пермского национального исследовательского политехнического университета.

Пойлов В.З., доктор технических наук, профессор, заведующий кафедрой химические технологии Химикотехнологического факультета Пермского национального исследовательского политехнического университета.

Мунин Д.А., магистр кафедры химические технологии Химико-технологического факультета Пермского национального исследовательского политехнического университета. 
UDC 661.832 .321

\title{
RESEARCH OF PULVERIZED HALURGIC POTASSIUM CHLORIDE AGGLOMERATION
}

\author{
Mariya V. Cherepanova', \\ syromyatnikova.maria@yandex.ru
}

\author{
Evgenia 0. Kuzina', \\ zena322myname@mail.ru
}

\author{
Vladimir Z. Poylov', \\ vladimirpoilov@mail.ru \\ Dmitry A. Munin',
demon011093@yandex.ru
'Perm National Research Polytechnic University,
29, Komsomolsky avenue, Perm, 614990, Russia.
}

The relevance. The industrial pulverized halurgic potassium chloride (KC1) is mixed with the finished conditioning product, which leads to its dustiness and caking, as well as losses during transportation. The enlargement of the pulverized KC1 will increase the quality of the main product, by eliminating the mixing stage of different components. The agglomeration by molding will make it possible to obtain a product of a size close to the concentrate. Investigation of agglomeration features with various binders will allow studying their influence on the efficiency of the process and the quality of the product obtained.

The main aim of the research is to study the molding of pulverized halurgic potassium chloride and to establish agglomeration features of moistened fertilizer using various binders.

Methods. To study the state of the agglomerates surface, electron-scanning microscopy was applied using the shooting modes BSE3D and SE with an increase to 1500X; to determine the elemental composition formed in molding and drying the fertilizer mixture, the Xray spectral analysis was used; the quality of the resulting product was evaluated using a sieve analysis and the method of measuring the static strength of an IPG-1M instrument.

The results. It was found that increasing the moisture content of the granulated mixture promotes an increase in the content of the commodity fraction to $84 \%$ and a static strength up to $10 \mathrm{~N} /$ granule; the use of binders has a positive effect on the quality of the product (increasing the yield and strength of the agglomerates), and they can have fundamentally different features of molding the pulverized halurgic KC1, resulting in formation of agglomerates with significant structural differences, as confirmed using electron microscopy. The use of sodium metasilicate makes it possible to obtain agglomerates with a tight adherence of particles to each other, and the needle-shaped crystals of silicon oxide formed by the thermal decomposition of $\mathrm{Na}_{2} \mathrm{SiO}_{3} \cdot 5 \mathrm{H}_{2} \mathrm{O}$ increase the roughness of the $\mathrm{KCl}$ particles, the number of crystallization centers, and strengthen the bonds in the granule. When molasses are used, the resulting agglomerates have KC1 particles with intimate contact, but the remainders of the binder are visible between them; on their surface there are accumulations of microparticles with a size of 10-30 $\mathrm{m}$ m of the initial pulverized raw materials in the form of "shell».

\section{Key words:}

Pulverized halurgic potassium chloride, granule, agglomeration, molding, electron microscopy, static strength, commodity fraction, particle.

\section{REFERENCE}

1. Gebreslassie H.B. Effect of Potasium Fertilizer on Crop Production. Journal of Natural Sciences Research, 2016, vol. 6, no. 7, pp. 81-86.

2. Neshev N., Manolov I. Potassium fertilizer rate and source influence content, uptake and allocation of nitrogen, phosphorus and potassium in potato plants. Conference VIVUS - on Agriculture, Environmentalism, Horticulture and Floristics, Food Production and Processing and Nutrition. Slovenia, Biotechnical Centre Naklo, 2017. Vol. 4, pp. 1-6.

3. Cherepanova M.V., Potapov I.S., Poylov V.Z., Popova K.V., Aliferova S.N. Influence of storage and transportation conditions on the physical and mechanical properties of granular potassium chloride. Bulletin of the Perm national research polytechnic university, 2012, no. 13, pp. 35-42. In Rus.

4. Nazarov V.I., Makarenko D.A. Complex fertilizers pelletizing and components rheological and physical properties. Bulletin of the Moscow region state university, 2011, no. 4, pp. 143-148. In Rus.

5. Haase K., Werth H., Probst H. Improved method of manufacturing an agglomerated potassium chloride fertilizer. Patent USA, no. $2107702,1938$.
6. Lipin A.G., Nebukin V.0., Lipin A.A. The encapsulation of granules in a polymer shells as a method of creation of mineral fertilizers with controlled speed of liberation of nutrients. Journal ISUCT. Modern High Technologies, 2017, no. 7 (51), pp. 86-91. In Rus.

7. Parfenyuk A.S., Kutnyashenko A.I., Tasits D.I., Khaynrikh Sh., Antonyuk S.I. Vozmozhnosti povysheniya effektivnosti pererabotki smesey prombytotkhodov putem granulirovaniya [Possibilities to increase the efficiency of processing mixtures of industrial waste through granulation]. Ekologicheskie problemy industrialnykh megapolisov: materialy III mezhdunarodnoy nauchnoprakticheskoy konferentsii [Ecological problems of industrial megacities: materials III International Scientific and Practical Conference. Proc. of the eighth All Ukraine scientific conference]. Ukraine, Donetsk Publ., 2010. Vol. 6, pp. 206-209.

8. Skovorodnikov P.V., Cherepanova M.V. The methods of granulation organomineral fertilizers. Bulletin of the Perm national research polytechnic university, 2017, no. 3, pp. 39-49. In Rus.

9. Iskandar A., Yuliasih I., Haryanto D.B. Effect of temperature and time on dry granulation process. International Journal of Research in Engineering and Technology, 2014, vol. 2, pp. 33-44. 
10. Vilesov N.G., Skhripkov V.Ya., Lomazov V.L., Tanchenko I.M. Protsessy granulirovaniya $v$ promyshlennosti [Granulation in industry]. Moscow, Tekhnika Publ., 1976. 192 p.

11. Fedotova 0.A. Razrabotka tekhnologii polucheniya granulirovannykh NPK udobreniy metodom okatyvaniya na osnove sulfata ammoniya $i$ khlorida kaliya, soderzhashchego primesi fotoreagentov. Dis. Kand. nauk [Development of technology for preparing granular NPK fertilizers by pelletizing on the basis of ammonium sulfate and potassium chloride containing impurities of photoreagents. Cand. Diss.]. Perm, 2012. 127 p.

12. Biskupski A., Schab S., Myka A., Dawidowicz M. Physicochemical properties of fertilizers available on market and possibility of production of blended fertilizers. Chemik, 2012, vol. 66, pp. 541-548.

13. GOST 21560.2-82. Udobreniya mineralnye. Metod opredeleniya staticheskoy prochnosti granul [State Standard 21560.2-82. Mineral fertilizers. Method for determination of granules static strength]. Moscow, Izdatelstvo stanfartov Publ., 2003. 7 p.

14. Titkov S.N., Matveev V.I., Kotlyar E.K., Shkuratskiy D.N. Sposob polucheniya khlorida kaliya [Method of obtaining potassium chloride]. Patent RF, no. 2652256, 2018.

15. Gluba T. The effect of wetting liquid droplet size on the growth of agglomerates during wet drum granulation. Powder Technology, 2003, no. 130, pp. 219-224.

16. Zhong Q., Li Q., Yang Y., Jiang T. Coal tar pitch and molasses blended binder for production of formed coal briquettes from high volatile coal. Fuel Processing Technology, 2017, vol. 25, pp. 89-97.

17. Volkov A.I., Zharskiy I.M. Bolshoy khimicheskiy spravochnik [Great chemical directory]. Moscow, Sovremennaya shkola Publ. $2005.608 \mathrm{p}$.

\section{Information about the authors}

Mariya V. Cherepanova, Cand. Sc., associate professor, Perm National Research Polytechnic University.

Vladimir Z. Poylov, Dr. Sc., professor, Perm National Research Polytechnic University.

Evgenia O. Kuzina, engineer, Perm National Research Polytechnic University.

Dmitry A. Munin, student undergraduate, Perm National Research Polytechnic University.
18. Kulkarni M.M., Bandyopadhyaya R., Bhattacharya B., Sharma A. Microstructural and mechanical properties of silica PEPEG polymer composite xerogels. Acta Materialia, 2006, no. 54, pp. 5231-5240.

19. Vehmas T., Kanerva U., Holt E. Spray-dry agglomerated nanoparticles in ordinary portland cement matrix. Materials Sciences and Applications, 2014, vol. 5, pp. 837-844.

20. Bernal S.A., Nicolas R.S., Deventer S.J., Provis J.L.Water content modifies the structural development of sodium metasilicateactivated slag binders. ALCONPAT Journal, 2015, vol. 5, pp. 30-41.

21. Korneev V.I., Danilov V.V. Rastvorimoe i zhidkoe [Soluble and liquid]. St. Petersburg, Stroyizdat. Publ., 1996. 216 p.

22. Cherepanova M.V., Poylov V.Z. Interaction of a potassium silicate binder with impurity components during formation of $\mathrm{KCl}$ granules by the pelletizing method. Bulletin of the Tomsk Polytechnic University. Geo Assets Engineering, 2017, vol. 328, no. 10, pp. 41-49. In Rus.

23. Grigoryev P.N., Matveev M.A. Rastvorimoe steklo: poluchenie, svoystva i primenenie [Soluble glass: production, properties and applications]. Moscow, State Publishing House of Literature on Building Materials, 1956. $443 \mathrm{p}$.

24. Filippovich E.N., Khatsrinov A.I., Skvortsov A.V. Choice of optimal conditions for thermal treatment of diatomite of the Inzen deposit of the Ulyanovsk region for the synthesis of crystalline sodium silicates. Bulletin of the Technological University, 2010, no. 5, pp. 83-86. In Rus.

Received: 25 December 2018. 